\title{
Investigation into PCB Routing Loss for Coupled Inductor Based VR (Voltage Regulator) Design in Server Computing System
}

\author{
Xiaoguo Liang1, Jinsong Zhu' ${ }^{1}$ Yinghua Ye', Yuan-Liang Li ${ }^{2}$ \\ ${ }^{1}$ Data Center Group in Intel Asia Pacific Research and Development Ltd., Shanghai, China \\ ${ }^{2}$ Date Center Group in Intel Microelectronics Asia LLC, Taiwan Branch, Taiwan \\ Email: Xiaoguo.liang@intel.com,jinsong.zhu@intel.com,yinghua.ye@intel.com,y.1.1i@intel.com
}

How to cite this paper: Liang, X.G., Zhu, J.S., Ye, Y.H. and Li, Y.-L. (2017) Investigation into PCB Routing Loss for Coupled Inductor Based VR (Voltage Regulator) Design in Server Computing System. Energy and Power Engineering, 9, 464-474. https://doi.org/10.4236/epe.2017.94B052

Received: March 2, 2017

Accepted: March 30, 2017

Published: April 6, 2017

\begin{abstract}
Coupled inductor is one appealing technology to improve transient response and reduce output decoupling significantly in interleaved multi-phase voltage regulators (VRs). One well known problem is that coupled inductor winding structure causes PCB routing path longer than discrete inductor design. This paper investigates possible PCB routing schemes for coupled inductor and conducts a fair and quantitative comparison with discrete inductor in a server VR design. Simulation and measurement are also conducted to verify the analysis.
\end{abstract}

\section{Keywords}

PCB Routing Loss, Coupled Inductor, Voltage Regulator (VR), Server

\section{Introduction}

According to the microprocessor's roadmap, there are several stringent challenges for the future microprocessor voltage regulators (VRs): high output current, low output voltage, high current slew rate and low droop resistance. These challenges require the VRs to have both higher steady state performance and faster transient performance. To improve above issues in today's multiphase non-coupled VRs, inversely coupled inductor VRs are proposed mainly to improve transient response significantly so that both real estate and cost could be saved on output decoupling [1] [2]. Some studies also shows that inversely coupled inductor could also help improve VR's conversion efficiency if keeping the same transient response as non-coupled multiphase VRs [3] [4]. With all these advantages, as shown in Figure 1, one well-known issue for coupled inductor based VR design is that inversely coupled structure of the inductor 
Phase 1

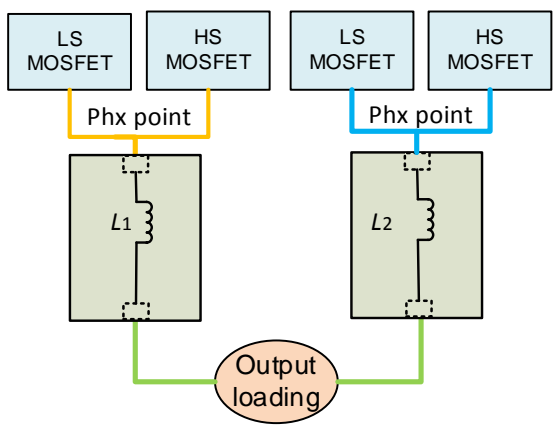

(a)

\section{Phase 2}

Extra power trace for coupled inductor design
Phase 1 Phase 2

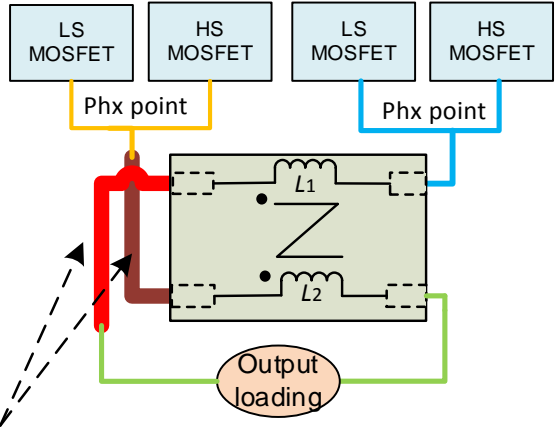

(b)

Figure 1. Layout trace difference for discrete idncutor vs. coupled inductor design (a) discrete inductor; (b) coupled inductor.

winding will make overall length of $\mathrm{PCB}$ routing trace longer than discrete inductor design, thus causes higher PCB trace impedance to have side effect on VR efficiency. As shown in Figure 1(b), the thick solid line illustrates extra power trace in a typical inversely coupled inductor design. It's a concern especially in such high current load application as server CPU core VRs. Previous papers have discussed some proposals to address this problem by adopting a new twisted magnetic core structure for coupled inductor [5] [6], however it's complicated from implementation viewpoint and not friendly for mass production to benefit industry. Moreover, there is still lacking of quantitative study of side impact on VR conversion efficiency from aforementioned problem by using coupled inductor. This paper has a detailed investigation into a real coupled inductor based server VR design, simulates the DC impedance of coupled inductor winding path with different layout schemes, compares the DC impedance of coupled inductor winding path with discrete inductor counterpart as well, finally conducts an quantitative analysis for the exact efficiency impact for coupled inductor design.

\section{Layout Improvements for Coupled Inductor Design for a Server CPU VR}

To meet both power integrity (PI) and signal integrity (SI) requirement, server real mother board is typically designed with $10-12$ layers PCB stackup today and all internal layers are normally $1 \mathrm{oz}$ copper thickness while top and bottom layers are $1.5 \mathrm{oz}$, and 10 layers motherboard design is more popular. One coupled inductor VR power evaluation board is built as a baseline for the analysis in this paper. It's built with 8 layers stackup to emulate real 10 layers situation in server motherboard. As shown in Figure 2, top and bottom layers are 1.5oz, internal layers are all $1 \mathrm{oz}$ except $2 \mathrm{oZ}$ for layer 4 and layer 5 . This stackup is equivalent to server 10 layers design (usually with two more 1oz GND layers) so that the analysis could be representative of real server motherboard application. 


\begin{tabular}{|c|c|c|c|c|}
\hline $\begin{array}{l}\text { Layer } \\
\text { Name }\end{array}$ & Plane Description & $\begin{array}{c}\text { Laywe } \\
\text { Thickness } \\
\text { (mil) }\end{array}$ & $\begin{array}{c}\text { Copper } \\
\text { Weight } \\
\text { (oz) }\end{array}$ & $\begin{array}{c}\text { Dielectric } \\
\text { (eR) }\end{array}$ \\
\hline & solder mask & 0.5 & & 3.8 \\
\hline \multirow[t]{2}{*}{ Signal 1(L1) } & SIGNAL & 1.9 & 1.5 & \\
\hline & & 2.7 & & 4.0 \\
\hline \multirow[t]{2}{*}{ Plane 2(L2) } & GND & 1.3 & 1.0 & \\
\hline & core & 4 & & 4.1 \\
\hline \multirow[t]{2}{*}{ Signal 3(L3) } & Sig/pwr & 1.3 & 1.0 & \\
\hline & pwepreg & 15 & & 4.0 \\
\hline \multirow[t]{2}{*}{ Plane 4(L4) } & Pwr/gnd & 2.6 & 2.0 & \\
\hline & core & 4 & & 4.1 \\
\hline \multirow[t]{2}{*}{ Plane 5(L5) } & Gnd & 2.6 & 2.0 & \\
\hline & & 15 & & 4.0 \\
\hline \multirow[t]{2}{*}{ Signal 6(L6) } & Sig/gnd & 1.3 & 1.0 & \\
\hline & core & 4 & & 4.1 \\
\hline \multirow[t]{2}{*}{ Plane 7(L7) } & GND & 1.3 & 1.0 & \\
\hline & mprepregu & 2.7 & & 4.0 \\
\hline \multirow[t]{3}{*}{ Signal 8(L8) } & SIGNAL & 1.9 & 1.5 & \\
\hline & solder mask & 0.5 & & 3.8 \\
\hline & tot & 62.6 & $+8 /-5$ & \\
\hline
\end{tabular}

Figure 2. Layout trace difference for discrete idncutor vs. coupled inductor design (a) discrete inductor; (b) coupled inductor.

In server form factor design, the height of inductor is relative relaxed and could be up to $8 \mathrm{~mm}$ typically, so DCR (DC resistance) of today's discrete inductor in server motherboard design is usually within the range of $0.15-0.3$ mohm by adopting thick copper of winding. Currently there are two most popularly adopted inductor skus, one is with DCR of $0.29 \mathrm{mohm}$, the other is with DCR of $0.19 \mathrm{mohm}$ [7] [8]. For coupled inductor design for server application, it's also doable to design its DCR of each winding to same level, i.e., DCR is controlled as $0.19 \mathrm{mohm}$. So this paper will mainly focus on analysis of the impedance difference of the power trace and its impact from motherboard routing side, rather than on the DCRs of inductors themselves. Moreover, it's feasible to control the physical size (both land pattern and height) of one coupled inductor to be equivalent to the total size of two discrete inductors in a two phases buck VR design, so that we can keep aforementioned advantages of coupled inductor such as transient and efficiency improvements for VR without the sacrifice of increasing motherboard real estate.

\subsection{Some Considerations for Coupled Inductor Layout Design}

For coupled inductor design, as shown in Figure 3, there are two possible layouts in motherboard placement. Figure 3(a) is a lateral layout in which both first phase inductor L1 and second phase inductor L2 have extra PCB trace routing represented by $\mathrm{Rd} 1$ and $\mathrm{Rd} 2$ respectively. It's obvious $\mathrm{Rd} 1$ and $\mathrm{Rd} 2$ are closely identical so this is a balanced design. By contrast, Figure 3(b) is a vertical layout in which first phase inductor L1 has no extra PCB trace rouging compared to that of a discrete inductor. Second phase inductor has more than 2 times extra PCB trace routing represented by Rc1 and Rc2 for back and forth routing. Obviously $\mathrm{Rc} 1$ is greater than $\mathrm{Rd} 1$ from straightforward comparison of trace routing length, and this is an imbalanced design. 
Phase 1 Phase 2

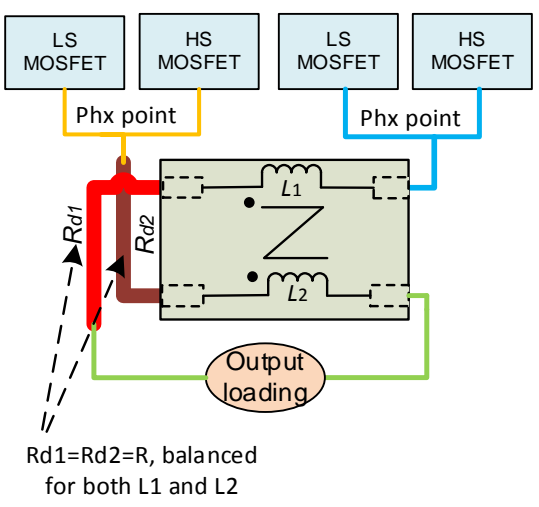

(a)
Phase 1 Phase 2

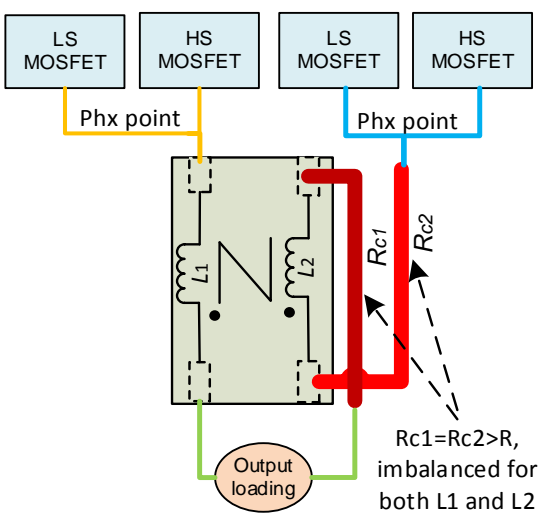

(b)

Figure 3. Two possible layouts for coupled inductor: (a). lateral layout (b). vertical layout.

Assuming $R_{d 1}=R_{d 2}=R$, then $R_{c 1}=R_{c 2}>R$. if each phase carries load current of I, it's easy to get total power loss from the extra PCB trace routing for both layouts:

$$
\begin{aligned}
& P_{\text {loss_lanteral }}=I^{2} R_{d 1}+I^{2} R_{d 2}=2 I^{2} R \\
& P_{\text {loss_vertical }}=I^{2}\left(R_{c 1}+R_{c 2}\right)>2 I^{2} R
\end{aligned}
$$

It's derived that power loss from extra PCB trace routing for vertical layout is higher than that for lateral layout. Using the real coupled inductor (length $=17$ $\mathrm{mm}$, width $=10 \mathrm{~mm})$ as an example the resistance of $R_{c 1}\left(R_{c 2}\right)$ is roughly 1.7 times $R_{d 1}\left(R_{d 2}\right)$, then total power loss from extra PCB trace routing for vertical layout is also roughly $70 \%$ higher than that for lateral layout. Besides, vertical layout of coupled inductor can cause potential current sharing and thermal imbalance between the two phases in spite of good current sharing scheme in today's VR controllers. In addition, the overall utilization of layout real estate for lateral layout is also better than vertical layout. Unless otherwise specified in this paper, all discussion and analysis are based on the lateral layout for coupled inductor in following sessions.

In the following, we will analyze several PCB layout schemes for coupled inductor design, then we will compare the difference of extra PCB trace routing for these schemes. Power DC CAD software, a well-known simulation tool for PCB layout in industry, is used to simulate resistance value of extra PCB trace routing for these schemes. Experimental test is also conducted to correlate to the simulation result of the first option (original design). It's to verify that Power DC is an accurate way to simulate DC resistance and so it's a reliable way to analyze other layout schemes without real implementations of those schemes.

\subsection{Scheme 1-Original Layout}

As shown in Figure 4, it's the original layout for coupled inductor power evaluation board. Two inductor winding symbols are also shown in the left snapshot (Top layer) to help easily understanding each winding routing direction and this 

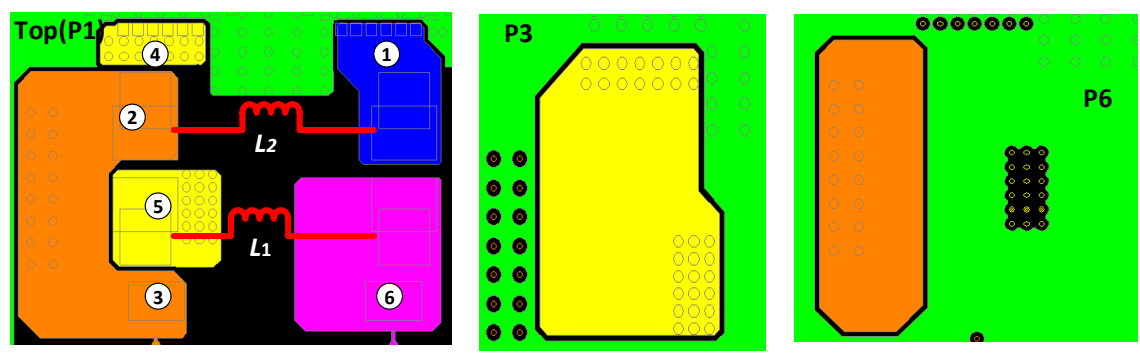

Figure 4. Original layout (Baseline) for coupled inductor power EVB.

is not shown anymore in after mentioned layout snapshots. This layout scheme has the following characteristics:

- Top layer is dominated and only limited utilization of internal layers (P3 and P6). the effectiveness of layer 6 (P6) is also limited. So resistance is bigger for extra PCB trace because vias location is relatively far from inductor pad to keep reasonable isolation space from power plane of $\mathrm{P} 3$.

- All internal GND layers are remained as complete ground layers.

- Impact on Internal layers is minimized, which is good for high speed signal routing and signal quality. Nevertheless, the overall occupancy of real estate on top layer is large, it could be a concern in real application.

\subsection{Scheme 2-Adding More Layers for Layout}

As shown in Figure 5, to improve the utilization of internal layers and reduce overall resistance of extra power trace routing, more internal layers (P3, P4, P6) and bottom layer (P8) are all used to route required traces for coupled inductor (L1, L2). This layout scheme is characteristic of the following:

- Top layer, bottom layer, more internal layers (P3, P4, P6) are utilized. So resistance could be reduced for extra PCB trace.

- All internal GND layers (P2, P5, P7) are kept complete.

- Impact on internal layers is minimized to benefit high speed signal routing and signal quality, and the overall occupancy of real estate on top layer is smaller and good for real application.

\subsection{Scheme 3-Adding More Copper Pours for Top Layer}

Figure 6 shows the other option of layout. It's similar to scheme 2 except for designing a complete copper pour on top layer. It's based on the fact that both outputs of L1 and L2 are tied together to the output of VR, so this small change can take full use of the available space on top layer to reduce the resistance of extra power trace routing.

\subsection{Scheme 4-Adding More Vias for Layout}

Figure 7 shows the last option by adding more vias into the routing area of extra power trace in scheme 3. The aforementioned three schemes actually have placed reasonable count of vias based on standard PCB routing guideline. This scheme is to investigate the impact of adding more vias. By the way, the inner 


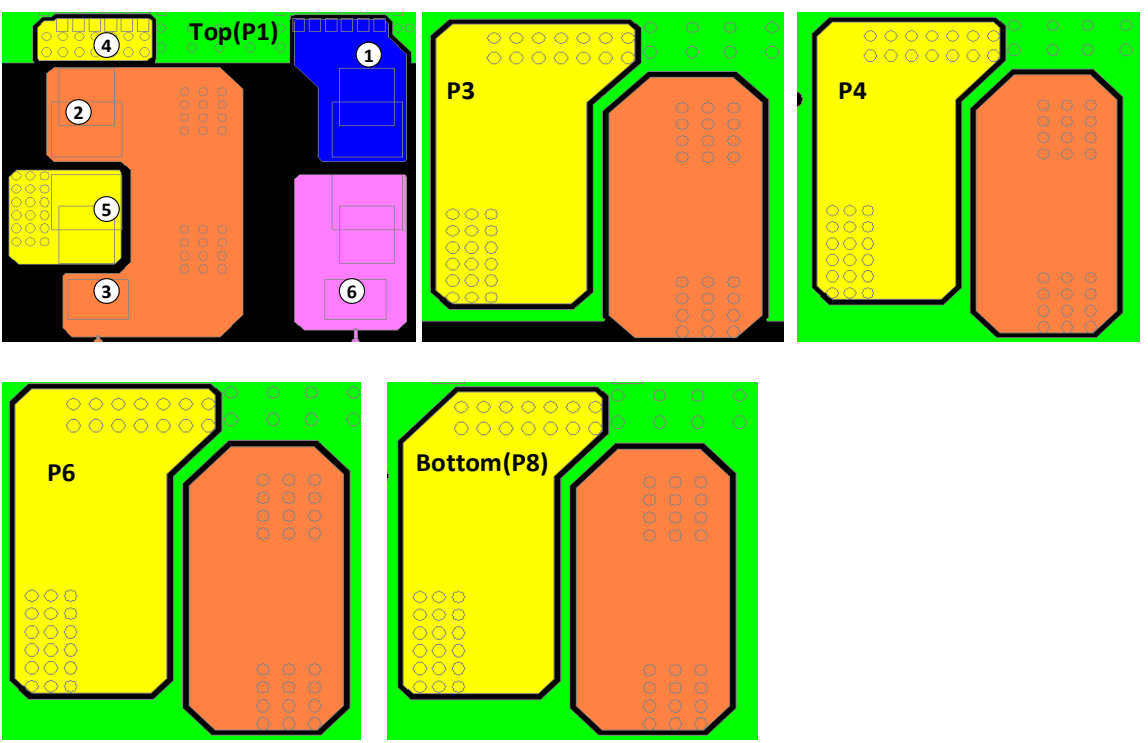

Figure 5. Scheme 2 improved layout by adding more internal layers.
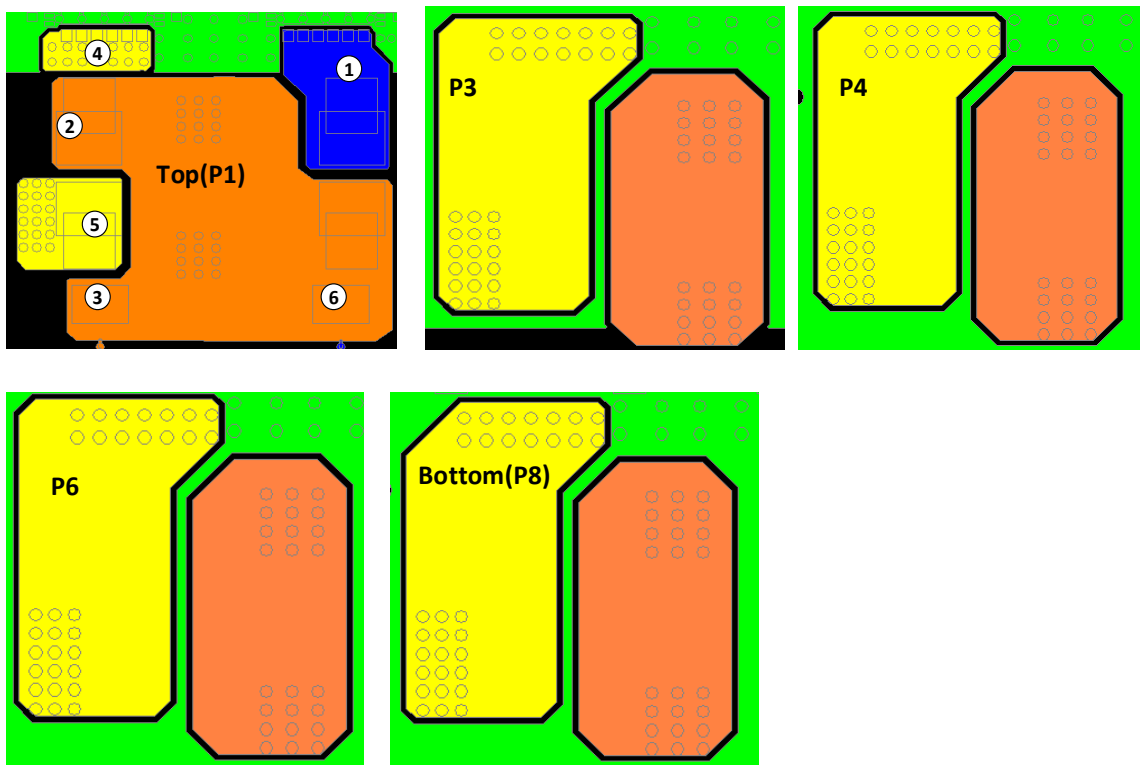

Figure 6. Scheme 3 improved layout by adding more copper pour on top layer.

diameter for all vias used in all layout schemes is $10 \mathrm{mil}$ and outer diameter is $20 \mathrm{mil}$ in size.

\section{Simulation \& Test Result}

Power DC CAD software is used to simulate DC resistance of extra power trace routing under different layout schemes. The simulation results are shown in Table 1. As marked in Figures 4-7, the DC resistance from point 1 to point 3(written as trace 1_3 in Table 1) represents extra power trace resistance of L2 and it could be split into two segments: point 1 to point 2 (written as trace $1 \_2$ in Table 1) and point 2 to point 3 (written as trace 2_3 in Table 1). Similarly, the DC resistance from point 4 to point 6 (trace $4 \_6$ in Table 1) represents extra 

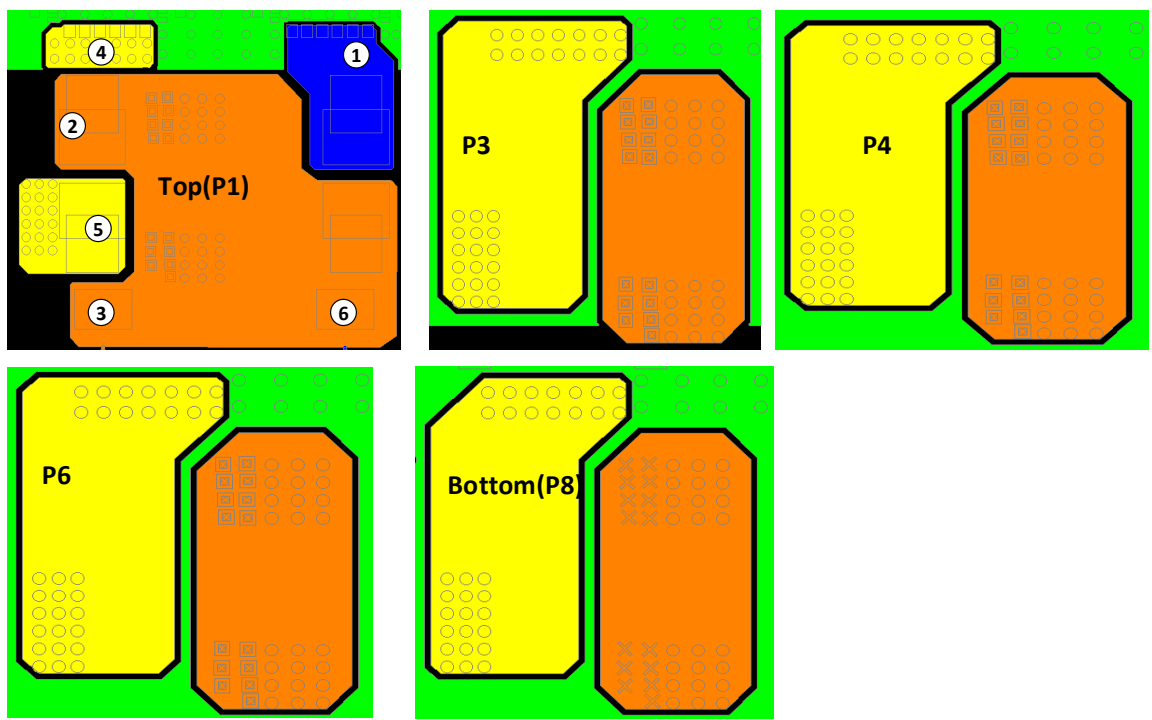

Figure 7. Scheme 4. improved layout by adding more vias.

Table 1. Impedance simulation result for coupled inductor in different layout options.

\begin{tabular}{ccccc}
\hline & scheme 1 & scheme 2 & scheme 3 & Scheme 4 \\
\hline Trace* & $(\mathrm{mohm})$ & $(\mathrm{mohm})$ & $(\mathrm{mohm})$ & $(\mathrm{mohm})$ \\
\hline $4 \_6$ & 1.353 & 0.94 & 0.889 & 0.874 \\
$4 \_5$ & 0.913 & 0.506 & 0.501 & 0.501 \\
$5 \_6$ & 0.44 & 0.434 & 0.388 & 0.373 \\
$1 \_3$ & 1.61 & 1.602 & 0.966 & 0.945 \\
$1 \_2$ & 0.54 & 0.602 & 0.586 & 0.586 \\
2_3 & 1.07 & 1 & 0.38 & 0.359 \\
\hline
\end{tabular}

*:exclude DCR, simulation assumed at 40 degree C.

power trace resistance of $\mathrm{L} 1$ and it could be separated into two segments: point 4 to point 5 (trace $4 \_5$ in Table 1 ) and point 5 to point 6 (trace 5_6 in Table 1). Besides, one typical server core VR design with discrete inductor is selected to conduct simulation to obtain power path resistance of discrete inductor. The simulated data is shown in Table 2 as comparison. Unless otherwise specified, all simulation data is based on two assumptions: a. at 40 degree $\mathrm{C}$ of copper temperature; b. exclusion of DCRs of both coupled and discrete inductors. So DCR is not a consideration in this paper.

It can been seen from Table 1:

- Original layout design (scheme 1) has the biggest extra power trace resistance with top layer routing dominated and limited internal layers utilized.

- By adding more internal layers, scheme 2 effectively reduces the associated resistance. Resistance of $4 \_6$ for $\mathrm{L} 1$ is reduced around 30\% (from $1.35 \mathrm{mohm}$ to $0.94 \mathrm{mohm}$ ) and the reduction of resistance of $1 \_3$ for L2 is very limited (from $1.61 \mathrm{mohm}$ to $1.6 \mathrm{mohm}$ ). The ineffectiveness for the resistance reduction of $1 \_3$ is mainly because those vias put at segment $2 \_3$ are relatively far from the pad of inductor L2, thus the load current still mainly flows across 
Table 2. Impedance simulation result for discrete inductor design.

\begin{tabular}{ccc}
\hline Trace & Imp. $(\mathrm{mohm})$ & Notes \\
\hline 1_6 (excl.DCR) & 0.62 & $@ 40$ degree C \\
DCR & 0.19 & \\
\hline
\end{tabular}

${ }^{\star} \mathrm{DCR}$ is from inductor spec, simulation based on 40 degree $\mathrm{C}$.

top layer path and make those added internal layers less ineffective.

- Scheme 3 is mainly to optimize resistance of $1 \_3$ by adding more copper pour at top layer. The reason is explained in scheme 2 description. It's effective because top layer copper plays a more important role. After this optimization, resistance of $4 \_6$ and $1 \_3$ is closed to each other and both are reduced by $\sim 34 \%$ from the original design.

- In scheme 4, adding more vias to the segment of 2_3 helps further reduction of resistance of $1 \_3$ and $4 \_6$ but is very limited. This is because there has been enough vias in previous options and those vias are not as close as possible yet to the pad of inductor L2.

To have a fair comparison, one typical server core VR design (6 phases) with discrete inductor is selected to conduct simulation of power trace routing resistance for discrete inductor counterpart. As shown in Figure 8, the same length as that for coupled inductor is used for location point choice of layout from starting point to end point for the interested resistance. Table 2 shows the simulation result for the PCB routing resistance for discrete inductor design. It can been seen that the extra PCB routing resistance for the original coupled inductor design is around 2.4X the discrete inductor design, and this number becomes around 1.4X after above mentioned layout optimization for the coupled inductor design,. From the viewpoint of relative comparison, the difference is still big. However, from absolute resistance value standpoint, the equivalent resistance of PCB routing for coupled inductor design (after optimization) is only $\sim 1 / 6 \mathrm{mohm}$ in total so that its impact on overall efficiency is still limited in a 6 phases VR design. Some more quantitative data will be presented in the next section. Besides, DCR of the discrete inductor is only $0.19 \mathrm{mohm}$, around $30 \%$ of total inductor associated impedance. It indicates, from the viewpoint of inductor relevant copper loss reduction, the main focus is on PCB routing instead of inductor winding itself for future. It is also noted that only top layer is used for typical discrete inductor design in server motherboard with the perception that it will benefit EMC noise.

Table 3 shows simulated and measured resistance of power trace routing for original coupled inductor design. The accuracy is within around 10\% range. It has been good enough from engineering standpoint if considering several factors: first, the copper thickness at top layer of real motherboard is typically more or less thicker than our theoretical data $(1.5 \mathrm{oZ})$, and it make simulation data little bit higher than what it should be; second, measuring such a sub-milliohm resistance is also a challenge, the test here is using one accurate DMM (digital multi-meter) to measure the voltage drop from switching point to the output 


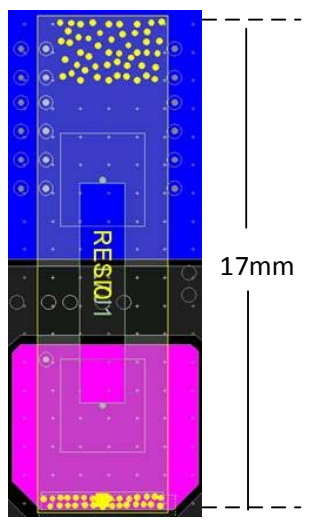

(a) Discrete inductor

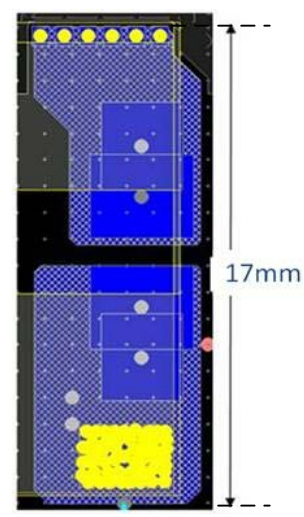

(b) Coupled inductor

Figure 8. Simulation location for discrete inductor vs. coupled inductor.

Table 3. Measurement vs. simulation resistance in original coupled inductor EVB.

\begin{tabular}{cccc}
\hline & Simulated & Measured & Error (\%) \\
\hline Trace $^{*}$ & $(\mathrm{mom})$ & $(\mathrm{mom})$ & \\
\hline $4 \_6$ & 1.353 & 1.25 & $8.24 \%$ \\
$1 \_3$ & 1.61 & 1.45 & $11 \%$ \\
\hline
\end{tabular}

voltage point as marked in Figure 4 by asserting a $10 \mathrm{~A}$ load current across the inductor. The temperature of copper of PCB top layer is also measured (40 degree $\mathrm{C}$ in this case) for simulation calibration.

\section{Efficiency Impact \& Overall Analysis}

As shown in Figure 9 and Figure 10, the efficiency curve for original coupled inductor design in a typical server CPU core VR is compared with that after considering removal of RMS loss of $\mathrm{PCB}$ routing extra trace resistance from coupled inductor. The aforementioned 8 layer power original EVB is used as baseline for comparison. It can be seen two efficiency curves overlaps almost within a whole load range from $0 \mathrm{~A}$ to $100 \mathrm{~A}$. A more detailed efficiency delta is also plotted to illustrate more quantitative insights. It can be seen that the extra PCB routing trace resistance of coupled inductor causes about $0.8 \%$ efficiency suffering at full load current of $100 \mathrm{~A}$ if without any layout improvement, and this number becomes less than $0.3 \%$ after above mentioned layout improvement. At light load (less than $10 \mathrm{~A}$ ), the efficiency suffering is less than $0.4 \%$ before layout improvement and the number is less than $0.15 \%$ after layout improvement. At CPU idle state (@6A load current), the efficiency suffering is around $0.2 \%$ before layout improvement and the number is less than $0.1 \%$ after layout improvement. There is some fluctuations for the curve of efficiency delta within load from $10 \mathrm{~A}$ to $100 \mathrm{~A}$. It's mainly because there is phase count change from 2 phases to 6 phases with increase of load current and the overall loss distribution is not showing a monolithic trend. It can be concluded, after layout improvement, the overall efficiency impact from the extra PCB routing resistance is very 


\section{EFFICEINCY CURVE FOR DIFFERENT INDUCTOR DESIGN}

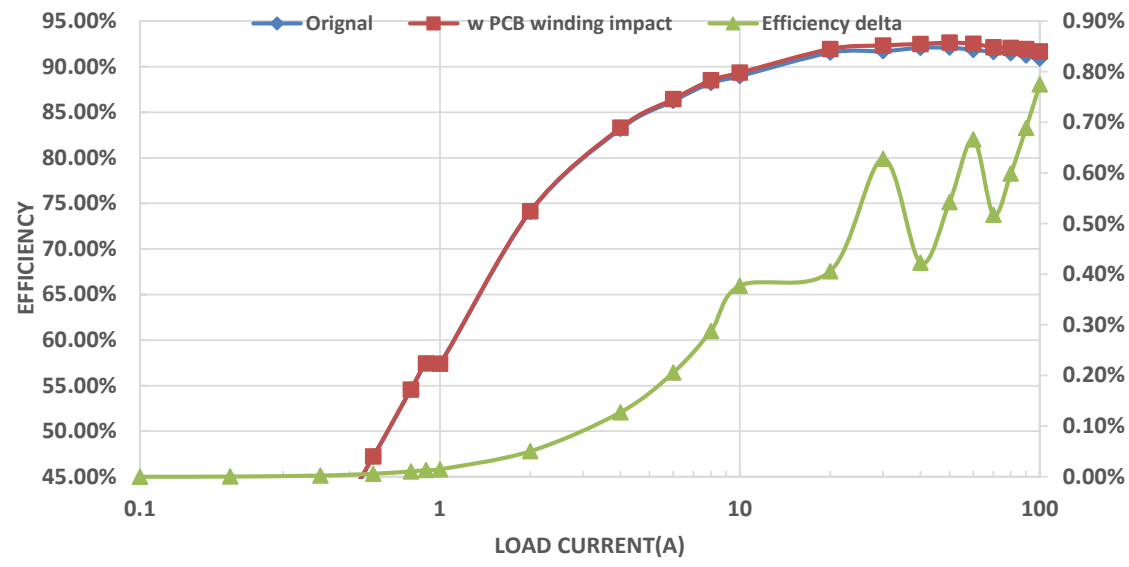

Figure 9. Efficiency impact analysis for orignal coupled inductor design before optimization.

EFFICEINCY CURVE FOR DIFFERENT INDUCTOR DESIGN

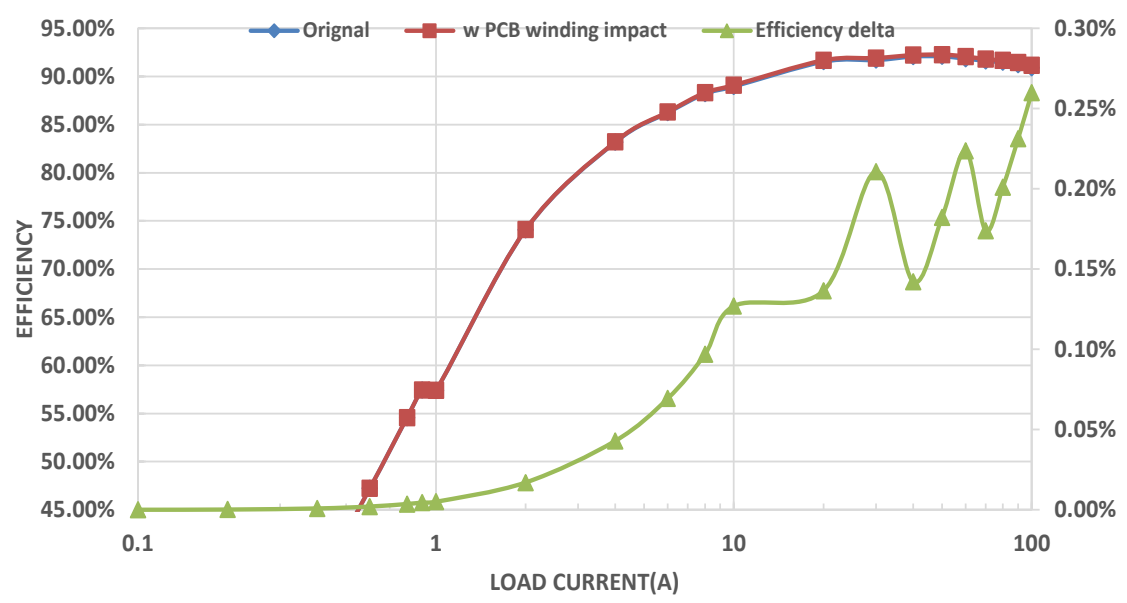

Figure 10. Efficiency impact analysis for coupled inductor design after optimization.

limited for the coupled inductor design.

Moreover, as can be seen from above analysis, discrete inductor design typically utilizes only top layer of motherboard as today's practice, while coupled inductor design has utilized more internal layers to optimize inductor routing resistance. Thus it's possible an argument that coupled inductor design could be noisier. It has the potential but it's a system level optimization task for EMC noise and beyond the scope of this paper. Nevertheless, there are some positive aspects to consider: First, the top layer copper usually could be thicker than standard stackup (1.5oz); Second, no high speed signals or sensitive signals are allowed to be routed under inductor area regardless of coupled or non-coupled inductor design, thus utilization of internal layers is not expected to cause obvious impact on signal quality or noise with careful layout design; Third, the statistics shows around $30 \%$ of servers in data center worldwide works at comatose 
state [9]. It means efficiency at idle current also plays a very important role and above analysis shows the impact of extra PCB routing resistance on idle state efficiency is so minor to be ignored.

\section{Conclusion}

This paper quantitatively analyzes the impact of extra PCB routing impedance of coupled inductor design on the overall VR efficiency in a typical server system. It can be concluded that the efficiency impact after layout optimization is less than $0.3 \%$ at the worst case of full load current and the impact is minor to be ignored at light load. The coupled inductor design is still a promising solution given its overall benefits from other aspects.

\section{Acknowledgements}

The author would like to acknowledge Chuanxi Wang to help finish related test to acquire required data.

\section{References}

[1] Dong, Y. and Sun, J.L., et al. (2007) The Light Load Issue of Coupled Inductor Laptop Voltage Regulators and its solutions. Proc. of IEEE APEC 2007, 1581-1587. https://doi.org/10.1109/apex.2007.357728

[2] Dong, Y., Lee, F.C. and Xu, M. (2008) Evaluation of Coupled Inductor Voltage Regulators. Proceedings of IEEE APEC2008, 831-837.

[3] Wu, W.K., Lee, F.C. and Schuellein, G. (2006) Multi-Phase Buck Converter Design with Two-Phase Coupled Inductors. Proceedings of IEEE APEC 2006, 487-492. https://doi.org/10.1109/apec.2006.1620582

[4] Zhu, G.Y., McDonald, B.A. and Wang, K.R. (2009) Modeling and Analysis of Coupled Inductors in Power Converters. Proceedings of IEEE APEC 2009, 83-89. https://doi.org/10.1109/apec.2009.4802637

[5] Dong, Y., Lee, F.C., Zhou, J.H., Wang, S. and Xu, M. (2007) Twisted Oore Coupled Inductors for Microprocessor Voltage Regulators. Proceedings of IEEE PESC 2007, 2386-2392.

[6] Dong, Y., Zhou, J.H. and Lee, F.C. (2008) Twisted Core Coupled Inductors for Microprocessor Voltage Regulators. IEEE Trans. on Power Electronics, 235, 2536-2545. https://doi.org/10.1109/TPEL.2008.2002067

[7] Inductor Specification, FP0906-R series, Cooper Bussmann, Sept. 2010.

[8] Inductor Specification, PA4390. XXXHL Series, Pulse Electronics.

[9] Koomey, J. and Taylor, J. (2015) New Data Supports Finding that 30 Percent of Servers are "Comatose" Indicating that Nearly a Third of Capital in Enterprise Data Centers is Waste. www.koomey.com 
Submit or recommend next manuscript to SCIRP and we will provide best service for you:

Accepting pre-submission inquiries through Email, Facebook, LinkedIn, Twitter, etc. A wide selection of journals (inclusive of 9 subjects, more than 200 journals)

Providing 24-hour high-quality service

User-friendly online submission system

Fair and swift peer-review system

Efficient typesetting and proofreading procedure

Display of the result of downloads and visits, as well as the number of cited articles Maximum dissemination of your research work

Submit your manuscript at: http://papersubmission.scirp.org/

Or contact epe@scirp.org 